\title{
X-ray photoelectron spectroscopy of piperidinium ionic liquids: A comparison to the charge delocalised pyridinium analogues
}

Shuang Men ${ }^{1,2^{*}}$, Peter Licence ${ }^{3}$, Chi-Linh Do-Thanh ${ }^{4}$, Huimin Luo ${ }^{5}$ and Sheng Dai ${ }^{2 *}$

\author{
1 School of Material Science and Engineering \\ Shenyang Ligong University \\ Shenyang, P. R. China \\ 110159 \\ 2 Chemical Sciences Division \\ Oak Ridge National Laboratory \\ Oak Ridge, United States \\ 37830 \\ 3 School of Chemistry \\ The University of Nottingham \\ Nottingham, UK \\ NG7 2RD \\ 4 Department of Chemistry \\ Joint Institute of Advanced Materials \\ University of Tennessee \\ Knoxville, United States \\ 37996
}

5 Energy and Transportation Science Division

Oak Ridge National Laboratory

Oak Ridge, United States

37830

To whom correspondence should be addressed:

menshuang@hotmail.com

dais@ornl.gov 


\begin{abstract}
In this study, nine piperidinium-based ionic liquids are analysed by X-ray photoelectron spectroscopy. The effect of alkyl substituent length and the nature of the anion on the electronic environment of the cation are investigated. The electronic environment of the hetero carbon and the cationic nitrogen is compared between two structurally similar cations, 1-octyl-1-methylpiperidinium $\left(\left[\mathrm{C}_{8} \mathrm{C}_{1} \mathrm{Pip}\right]^{+}\right)$versus 1-octylpyridinium $\left(\left[\mathrm{C}_{8} \mathrm{Py}\right]^{+}\right)$. Due to the charge delocalisation, the hetero carbon component within $\left[\mathrm{C}_{8} \mathrm{Py}\right]^{+}$is more positively charged, which exhibits much higher binding energy; whilst the cationic nitrogen component is in the similar electronic environment. The impact of the charge delocalisation on the electronic environment of the anion is also compared between $\left[\mathrm{C}_{8} \mathrm{C}_{1} \mathrm{Pip}\right]^{+}$and $\left[\mathrm{C}_{8} \mathrm{Py}\right]^{+}$. It is found that for the more basic anion, the cation can significantly affect the electronic environment of the anion; for the less basic anion, such an effect concentrates on the component bearing more negative point charges.
\end{abstract}

Keywords: Piperidinium; Ionic liquids; X-ray photoelectron spectroscopy; Cation-anion interactions

\title{
Introduction
}

Ionic liquids (ILs) have generated considerable excitement, ascribed to their liquid nature and negligible volatility. Being composed of cations and anions, they have shown many characteristic properties, i.e. low melting point, high thermal stability and high conductivity, and therefore been attractive for many practical applications. ${ }^{1-7}$ It has been concluded that by simply changing the cationic and/or anionic constituent, the physicochemical properties of ILs can be effectively tuned.

Piperdinium has been the most versatile family in applications next to imidazolium and pyridinium. Due to the lack of more acidic protons, piperidinium ILs often show higher thermal stability than imidazolium or pyridinium ILs. ${ }^{8,9}$ When compared to their structurally similar charge delocalised pyridinium analogues, piperdinium ILs often show higher melting points. For example, the melting point for $\left[\mathrm{C}_{4} \mathrm{C}_{1} \mathrm{Pip}\right] \mathrm{Br}$ is $514 \mathrm{~K}$, which is $136 \mathrm{~K}$ higher than that of $\left[\mathrm{C}_{4} \mathrm{Py}\right] \mathrm{Br} .{ }^{10}$ However, for a specific case, i.e. switching the anion of the above two ILs to the larger delocalised bis (trifluoromethanesulfonyl)imide $\left(\left[\mathrm{Tf}_{2} \mathrm{~N}\right]\right.$ ) ), the melting point of $\left[\mathrm{C}_{4} \mathrm{C}_{1} \mathrm{Pip}\right]\left[\mathrm{Tf}_{2} \mathrm{~N}\right]$ is found $48 \mathrm{~K}$ below that of $\left[\mathrm{C}_{4} \mathrm{Py}\right]\left[\mathrm{Tf}_{2} \mathrm{~N}\right] \cdot{ }^{11}$ Apart from those, piperidinium ILs also show higher viscosity $8,12,13$ and wider electrochemical windows, ${ }^{14,15}$ compared to imidazolium or pyridinium ILs. All the above properties have made piperdinium ILs potentially useful particularly in electrochemical applications.

To date, X-ray photoelectron spectroscopy (XPS) has been accepted as an effective tool to investigate ionic liquid-based systems. ${ }^{16,17}$ The focus of research effort in the area of ultrahigh vacuum (UHV) characterisation has been upon a host of families of ILs, including imidazolium, ${ }^{18}$, 19 pyridinium, ${ }^{20}$ pyrrolidinium, ${ }^{21}, 22$ ammonium, ${ }^{23}$ 
guanidinium ${ }^{24}$ and phosphonium. ${ }^{23}, 25$ The analysis initially includes the calculation of surface composition of ILs, the identifying of a certain component present in an ionic liquid, and the distinguishing of subtle change in electronic environment for either a cation- or an anion-based component. The scope of such a research topic is later extended to the investigation of the cation-anion interactions, which have also been probed by $\mathrm{NMR}^{26}$ and Kamlet-Taft parameters. ${ }^{27}$ The study of the cation-anion interactions of ILs aids proper understanding of their physicochemical properties.

In this work, XPS is used to analyse nine piperidinium-based ILs. The effect of the alkyl chain length on the electronic environment of the cation is investigated by varying $n$ from 2 to 12 . It is found that the charge-transfer effect from the anion to the cation and the inductive effect from the alkyl substituent can both affect the electronic environment of the cation-based components, i.e. $\mathrm{N}_{\text {cation }} 1 \mathrm{~s}$. The $\mathrm{C}_{\text {hetero }} 1 \mathrm{~s}$ binding energy is compared between $\left[\mathrm{C}_{8} \mathrm{C}_{1} \mathrm{Pip}\right]^{+}$and $\left[\mathrm{C}_{8} \mathrm{Py}\right]^{+}$. Due to the charge delocalisation, the hetero carbon component within $\left[\mathrm{C}_{8} \mathrm{Py}\right]^{+}$is more positively charged, which exhibits much higher binding energy. The charge delocalisation for $\left[\mathrm{C}_{8} \mathrm{Py}\right]^{+}$seems to affect the electronic environment of the nitrogen centre in a similar magnitude with the inductive effect of the additional methyl group for $\left[\mathrm{C}_{8} \mathrm{C}_{1} \mathrm{Pip}\right]^{+}$. It shows that the cationic $\mathrm{N} 1 \mathrm{~s}$ binding energy is identical for $\left[\mathrm{C}_{8} \mathrm{C}_{1} \mathrm{Pip}\right]^{+}$and $\left[\mathrm{C}_{8} \mathrm{Py}\right]^{+}$. The impact the cation on the electronic environment of the anion is also studied. It concludes that for the more basic anion, i.e. $\mathrm{Br}$, the binding energy shift of $\mathrm{Br} 3 \mathrm{~d}_{5 / 2}$ is noticeable (more than $0.2 \mathrm{eV}$ ); for the less basic anion, i.e. $\left[\mathrm{Tf}_{2} \mathrm{~N}\right]$; such a change in electronic environment is found concentrated on $01 \mathrm{~s}$.

\section{Experimental}

\section{Materials}

All chemicals were purchased from Sigma Aldrich and were used as received. Ionic liquids investigated in this study were prepared in our laboratory using established synthetic protocols, and were characterised by NMR recorded on a JEOL 400YH spectrometer as solutions in DMSO- $d_{6}$. The procedures of synthesis of ionic liquids, NMR data and XP spectra of ionic liquids are demonstrated in detail in Electronic Supplementary Information.

Table 1 All piperidinium ionic liquids studied in this paper.

\begin{tabular}{lll}
\hline Abbreviation & Structure & Name \\
\hline$\left[\mathrm{C}_{2} \mathrm{C}_{1} \mathrm{Pip}\right] \mathrm{Br}$ & & $\begin{array}{l}\text { 1-Ethyl-1-methylpiperidinium } \\
\text { bromide }\end{array}$ \\
{$\left[\mathrm{C}_{4} \mathrm{C}_{1} \mathrm{Pip}\right] \mathrm{Br}$} & & 1-Butyl-1-methylpiperidinium \\
\end{tabular}




1-Octyl-1-methylpiperidinium
bromide
1-Dodecyl-1-methylpiperidinium
bromide
1-Ethyl-1-methylpiperidinium
bis (trifluoromethanesulfonyl)imide

Note: $\left[\mathrm{C}_{8} \mathrm{Py}\right]\left[\mathrm{Tf}_{2} \mathrm{~N}\right]$ is also listed in this table for the comparison of the structure.

\section{XPS Data Collection}

All XP spectra were recorded using a Thermo Scientific $\mathrm{K}_{\alpha}$ spectrometer employing a focused, monochromated $\mathrm{Al} \mathrm{K}_{\alpha}$ source $(h v=1486.6 \mathrm{eV})$, hemispherical analyser, charge neutraliser and a 128-channel detector. The instrument employs an oval X-ray spot. The largest spot size (long axis) is 400 microns.

All ionic liquid (IL) samples prepared in this work were purified under high vacuum at $60{ }^{\circ} \mathrm{C}$ for at least $12 \mathrm{~h}$ prior to use. The IL sample was firstly transferred into a load-lock of the XPS instrument as a sample droplet on a stainless sample holder. Pumping of samples was conducted to achieve $\sim 10^{-4}$ mbar. After achieving the base pressure in the load-lock, samples were maintained pumping overnight, before transferring to the main analytical chamber.

The base pressure in the main analytical chamber is below $1 \times 10^{-9}$ mbar without any samples being analysed. When analysing liquid samples, the charge neutraliser is switched off which helps the maintenance of the pressure to be below $\sim 10^{-8} \mathrm{mbar}$. When solid samples are being analysed, the charge neutraliser is turned on. The pressure in this case is usually below $\sim 10^{-7}$ mbar. It suggests that all volatile impurities under those vacuum conditions, such as water and organic solvents, can be completely removed, leading to high purity samples. ${ }^{28}$ Consequently, the comparison of binding energies derived from XP spectra is reliable. 


\section{XPS Data Analysis}

CasaXPS software was used for data interpretation. A spline linear background subtraction was used. Peaks were fitted using GL (30) lineshapes: a combination of a Gaussian (70\%) and Lorentzian (30\%).29, 30 Relative sensitive factors for all elements are taken from literature. ${ }^{29}$

To aid visual interpretation of the XP spectra, all spectra were normalised to the fitted area of the cationic $\mathrm{N} 1 \mathrm{~s}$ peak of $\left[\mathrm{C}_{8} \mathrm{C}_{1} \mathrm{Pip}\right]\left[\mathrm{Tf} \mathrm{f}_{2} \mathrm{~N}\right]$, simply because the cationic nitrogen atom is present in all ionic liquids in the same amount.

For $n=8, C_{\text {aliphatic }} 1 \mathrm{~s}$ component was selected as an internal reference and was set to $285.0 \mathrm{eV}$ for the purpose of charge correction. For other $n$ values, $\mathrm{N}_{\text {cation }} 1 \mathrm{~s}$ was charge corrected to the value that obtained for $\mathrm{C}_{8}$-based analogues within a definite anion family. ${ }^{18,21} \mathrm{XP}$ spectra for $\left[\mathrm{C}_{8} \mathrm{Py}\right]^{+}$ILs are not measured in this study, but are available in a previous paper published by our group. ${ }^{20}$

\section{Results and discussion}

\section{Sample purity}

The sample purity of ILs is confirmed by semi-quantitative analysis from XPS. The experimental surface composition for each IL is calculated from high resolution XP spectra, according to the relative sensitivity factor for each element taken from literature. ${ }^{29}$ Table 2 demonstrates the surface composition for each of the IL studied in this paper. In order to give a visual comparison, the nominal stoichiometry is also included. Taking into account the error of semi-quantitative analysis from XPS, it suggests that the experimental surface composition is the same with the nominal one calculated from the empirical formulae, for each of the IL in this study.

Table 2 Experimental (calculated from XPS) and nominal stoichiometry for all ionic liquids studied in this paper

\begin{tabular}{llccccccc}
\hline \multirow{2}{*}{ Ionic Liquids } & RSF29 & $\mathrm{C} 1 \mathrm{~s}$ & $\mathrm{~N} \mathrm{1s}$ & $\mathrm{F} \mathrm{1s}$ & $\mathrm{O} 1 \mathrm{~s}$ & $\mathrm{~S} 2 \mathrm{p}$ & $\mathrm{P} 2 \mathrm{p}$ & $\mathrm{Br} 3 \mathrm{~d}$ \\
& & 0.278 & 0.477 & 1.000 & 0.780 & 0.668 & 0.486 & 1.055 \\
\hline$\left[\mathrm{C}_{2} \mathrm{C}_{1} \mathrm{Pip}\right] \mathrm{Br}$ & Measured & 8.5 & 0.8 & & & & & 0.7 \\
& (Nominal) & $(8.0)$ & $(1.0)$ & & & & & $(1.0)$ \\
{$\left[\mathrm{C}_{4} \mathrm{C}_{1} \mathrm{Pip}\right] \mathrm{Br}$} & Measured & 10.3 & 0.9 & & & & & 0.8 \\
& (Nominal) & $(10.0)$ & $(1.0)$ & & & & $(1.0)$ \\
{$\left[\mathrm{C}_{8} \mathrm{C}_{1} \mathrm{Pip}\right] \mathrm{Br}$} & Measured & 14.3 & 0.9 & & & & 0.8 \\
& (Nominal) & $(14.0)$ & $(1.0)$ & & & & $(1.0)$ \\
{$\left[\mathrm{C}_{12} \mathrm{C}_{1} \mathrm{Pip}\right] \mathrm{Br}$} & Measured & 18.3 & 0.9 & & & & 0.8 \\
& (Nominal) & $(18.0)$ & $(1.0)$ & & & & $(1.0)$ \\
{$\left[\mathrm{C}_{2} \mathrm{C}_{1} \mathrm{Pip}\right]\left[\mathrm{Tf} \mathrm{F}_{2} \mathrm{~N}\right]$} & Measured & 10.6 & 2.0 & 6.0 & 3.7 & 1.7 & \\
& (Nominal) & $(10.0)$ & $(2.0)$ & $(6.0)$ & $(4.0)$ & $(2.0)$ &
\end{tabular}




\begin{tabular}{llcccccc}
{$\left[\mathrm{C}_{4} \mathrm{C}_{1} \mathrm{Pip}\right]\left[\mathrm{Tf}_{2} \mathrm{~N}\right]$} & Measured & 12.7 & 2.2 & 5.8 & 3.7 & 1.7 & \\
& (Nominal) & $(12.0)$ & $(2.0)$ & $(6.0)$ & $(4.0)$ & $(2.0)$ & \\
{$\left[\mathrm{C}_{8} \mathrm{C}_{1} \mathrm{Pip}\right]\left[\mathrm{Tf} \mathrm{F}_{2} \mathrm{~N}\right]$} & Measured & 16.7 & 2.0 & 5.9 & 3.6 & 1.8 & \\
& (Nominal) & $(16.0)$ & $(2.0)$ & $(6.0)$ & $(4.0)$ & $(2.0)$ & \\
{$\left[\mathrm{C}_{12} \mathrm{C}_{1} \mathrm{Pip}\right]\left[\mathrm{Tf}_{2} \mathrm{~N}\right]$} & Measured & 20.9 & 1.8 & 5.8 & 3.8 & 1.7 & \\
& (Nominal) & $(20.0)$ & $(2.0)$ & $(6.0)$ & $(4.0)$ & $(2.0)$ & \\
{$\left[\mathrm{C}_{8} \mathrm{C}_{1} \mathrm{Pip}\right]\left[\mathrm{PF}_{6}\right]$} & Measured & 14.5 & 0.9 & 5.7 & & & 0.9 \\
& (Nominal) & $(14.0)$ & $(1.0)$ & $(6.0)$ & & & $(1.0)$ \\
\hline
\end{tabular}

\section{Electronic environment of the carbon regions: Fitting model}

Initially, the C 1s spectrum was fitted according to an established model developed for 1-alkyl-1-methylpyrrolidinium ILs reported in literature. ${ }^{21}$ Figure S1 shows the fitting of the $\mathrm{C} 1 \mathrm{~s}$ spectrum for $\left[\mathrm{C}_{8} \mathrm{C}_{1} \mathrm{Pip}\right]\left[\mathrm{Tf}_{2} \mathrm{~N}\right]$, wherein three components are used: $\mathrm{C}_{\text {hetero }}$ represents carbon atoms bonded directly to the positive charged nitrogen centre; $\mathrm{C}_{\text {inter }}$ represents carbon atoms which are $\beta$ to the cationic nitrogen; $\mathrm{C}_{\text {aliphatic }}$ represents the remaining carbon atoms locating further enough from the cationic nitrogen and bonded to carbon and hydrogen atoms only. This model allows a satisfactory fitting of the $\mathrm{C} 1 \mathrm{~s}$ region for $\left[\mathrm{C}_{8} \mathrm{C}_{1} \mathrm{Pip}\right]\left[\mathrm{Tf}_{2} \mathrm{~N}\right]$.However, the above model is found to be inapplicable for either $\left[\mathrm{C}_{8} \mathrm{C}_{1} \mathrm{Pip}\right]\left[\mathrm{PF}_{6}\right]$ or $\left[\mathrm{C}_{8} \mathrm{C}_{1} \mathrm{Pip}\right] \mathrm{Br}$. As shown in Figure $\mathrm{S} 2$, for both cases, the binding energies for $\mathrm{C}_{\text {inter }} 1 \mathrm{~s}$ and $\mathrm{C}_{\text {aliphatic }} 1 \mathrm{~s}$ are electronic identical by using the three-component fitting model. Therefore, it concludes that the three-component model is not always reliable for the purpose of the $\mathrm{C} 1 \mathrm{~s}$ spectra fitting for 1-alkly-1-methylpiperidinium ILs (more details can be found in Electronic Supplementary Information).

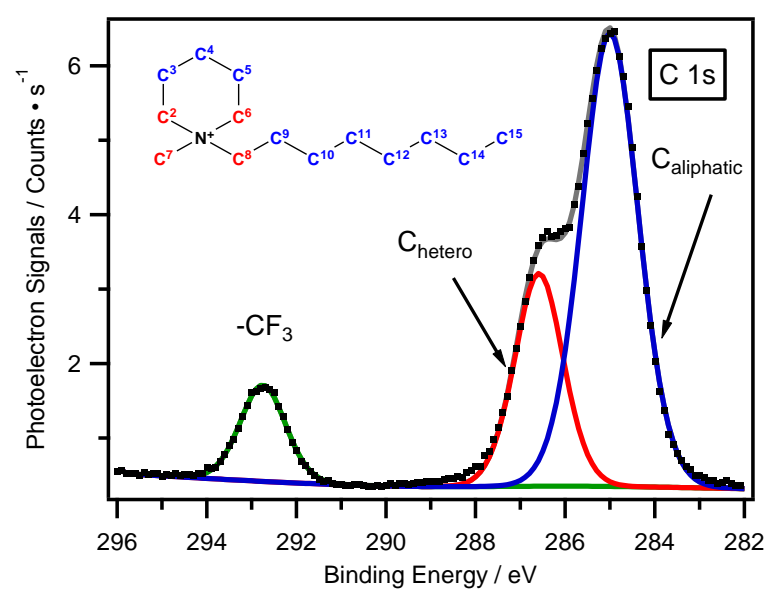

Figure $1 \mathrm{C} 1 \mathrm{~s}$ high resolution spectrum with fittings for $\left[\mathrm{C}_{8} \mathrm{C}_{1} \operatorname{Pip}\right]\left[\mathrm{Tf}_{2} \mathrm{~N}\right]$, with the structure of the cation included. A two-component model is used for the fitting: $\mathrm{C}_{\text {hetero }} 1 \mathrm{~s}$ ( $\mathrm{C}^{2}$ and $\mathrm{C}^{6}$ to $\mathrm{C}^{8}$ ) and $\mathrm{C}_{\text {aliphatic }} 1 \mathrm{~s}\left(\mathrm{C}^{3}\right.$ to $\mathrm{C}^{5}$ and $\mathrm{C}^{9}$ onwards).

Therefore, a two-component model (apart from the signal originated from $-\mathrm{CF}_{3}$ 
group) is developed. Figure 1 shows the fitting procedure for $\left[\mathrm{C}_{8} \mathrm{C}_{1} \mathrm{Pip}\right]\left[\mathrm{Tf} \mathrm{f}_{2} \mathrm{~N}\right]$. The structure of the cation is also included for visual comparisons. $\mathrm{C}_{\text {hetero }}$ is assigned to the carbon atoms bonded directly to the positively charged nitrogen; $\mathrm{C}_{\text {aliphatic }}$ represents to the carbon atoms bonded solely to carbon and hydrogen atoms. By constraining the area ratio of $\mathrm{C}_{\text {hetero }}: \mathrm{C}_{\text {aliphatic }}=4: 10$, a very satisfactory fitting can be achieved. The Full Width at Half Maximum (FWHM) ratio of $\mathrm{C}_{\text {aliphatic }}: \mathrm{C}_{\text {hetero }}$ is $\sim 1.2$, as the aliphatic component is actually an overlap of more carbon signals, which produces a characteristic broader feature. ${ }^{31,32}$ When varying $n$ values, simply changing the constraint of area ratio to $C_{\text {hetero }}$ : $\mathrm{C}_{\text {aliphatic }}=4:(n+2)$, where $n=2-12$, satisfactory fittings can be obtained.

$\left[\mathrm{C}_{n} \mathrm{C}_{1} \mathrm{Pip}\right] \mathrm{Br}$, where $n=2-12$, and $\left[\mathrm{C}_{8} \mathrm{C}_{1} \mathrm{Pip}\right]\left[\mathrm{PF}_{6}\right]$ contain no $-\mathrm{CF}_{3}$ group in the structure. Therefore, only the unresolved cation-based doublet $\mathrm{C} 1 \mathrm{~s}$ peak can be observed. However, the same fitting procedure is also applicable for these ILs.

\section{Effect of alkyl chain length on the aliphatic $\mathrm{C}$ 1s binding energies}

In order to investigate the effect of alkyl chain length on $\mathrm{C}_{\text {aliphatic }} 1 \mathrm{~s}$ binding energies, two families of ionic liquids are employed: one of the least basic anions, i.e. [ $\left.\mathrm{Tf}_{2} \mathrm{~N}\right]$; and $\mathrm{Br}$, which is a typical more basic anion. Figure 2 shows the $\mathrm{C} 1 \mathrm{~s}$ XP spectra for these two IL families.

As demonstrated in Figure 2a, for $\left[\mathrm{Tf}_{2} \mathrm{~N}\right]$; , there is an apparent shift of $\mathrm{C}_{\text {aliphatic }} 1 \mathrm{~s}$ binding energy towards higher value, along with the decreasing of the alkyl chain length, i.e. from dodecyl to ethyl. When $n=4$, the $C_{\text {aliphatic }} 1$ s binding energy is found at $285.2 \mathrm{eV}$, which is $0.2 \mathrm{eV}$ higher than that for $n=8$. This is because the alkyl carbons present in $\left[\mathrm{C}_{4} \mathrm{C}_{1} \mathrm{Pip}\right]^{+}$locates more closed to the positively charged nitrogen. Therefore, the inductive effect from alkyl chain to the positive headgroup leads to the decrease of the electron density on the alkyl carbon component, which subsequently shows higher binding energy. As the alkyl chain length decreases from butyl to ethyl, the $\mathrm{C}_{\text {aliphatic }} 1 \mathrm{~s}$ binding energy is further increased to $285.3 \mathrm{eV}$. It must be noted that when $n=12$, the $\mathrm{C}_{\text {aliphatic }} 1 \mathrm{~s}$ binding energy is $284.9 \mathrm{eV}$, which is $0.1 \mathrm{eV}$ lower than that for $n=8$. Since the experimental error associated with XPS is of the order $\pm 0.1 \mathrm{eV}$, a noticeable change in binding energy should be no less than $0.2 \mathrm{eV}$. Therefore, it suggests that when increasing $n$ value from 8 to 12 , the electronic environment of $C_{\text {aliphatic }} 1$ s component is not changed. This observation is in good agreement with the conclusion that has been made for pyridinium ionic liquids. ${ }^{20}$ As a result, it is concluded that the electronic environment of $\mathrm{C}_{\text {aliphatic }} 1$ s component is always identical when $n \geq 8$.

From another point of view, for more basic anions, i.e. Br-, the $\mathrm{C}_{\text {aliphatic }} 1 \mathrm{~s}$ binding energy is always identical by varying $n$ from 2 to 12, as shown in Figure $2 \mathrm{~b}$. It has been accepted that the $C_{\text {aliphatic }} 1 \mathrm{~s}$ binding energy is determined by two sets of effect: the inductive effect from the alkyl substituent towards the cation headgroup and the cation-anion interactions through charge-transfer from the anion to the cation. In the 
case of more basic anions, cations and anions are tightly paired leading to a weak inductive effect. Therefore, the changing of alkyl chain length cannot affect the $\mathrm{C}_{\text {aliphatic }} 1 \mathrm{~s}$ binding energy. However, in the case of less basic anions, the charge-transfer effect is negligible which causes an intense inductive effect. As a result, noticeable changes in electronic environment of the aliphatic carbon component can be observed.
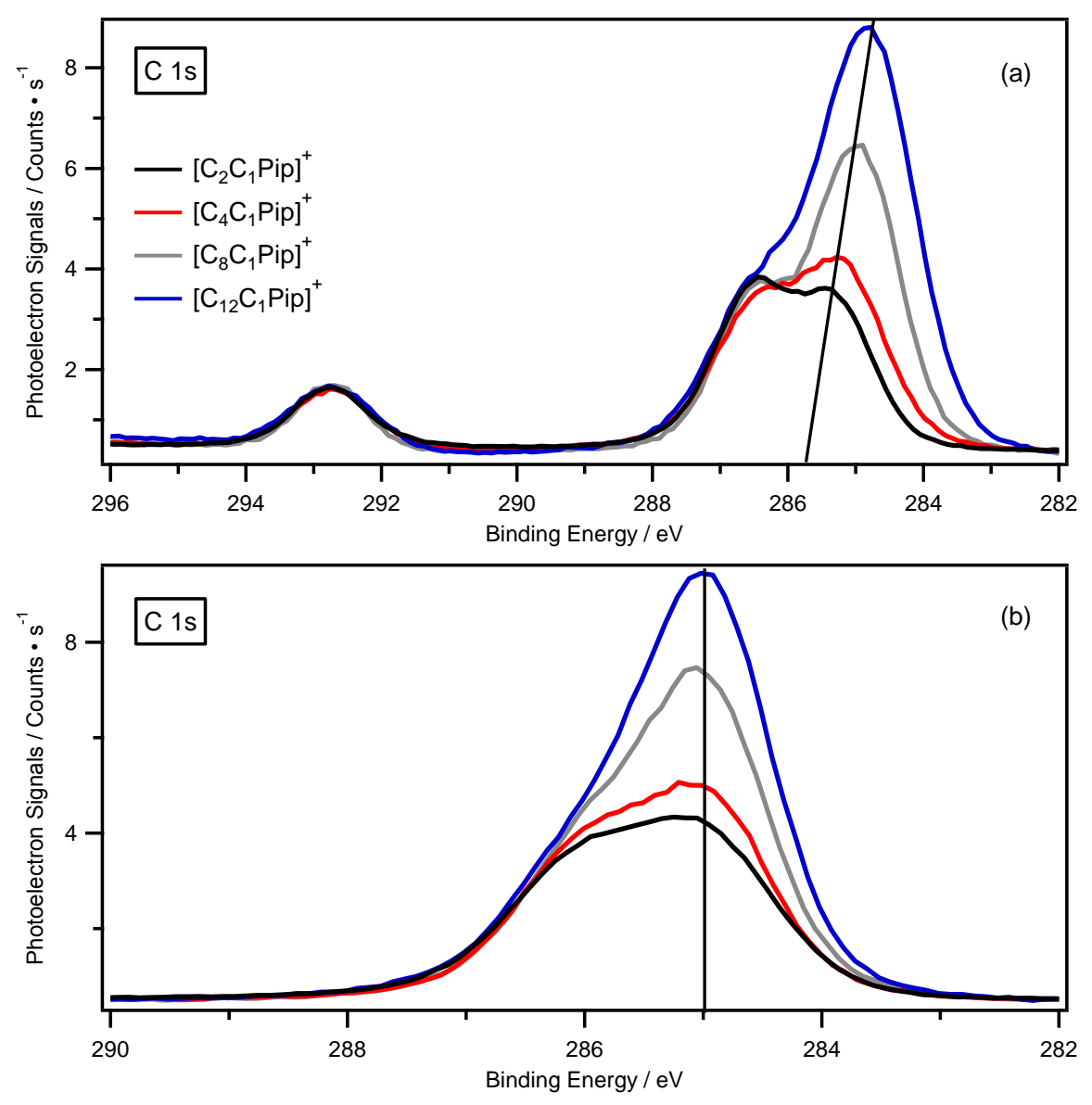

Figure $2 \mathrm{C} 1 \mathrm{~s}$ XP spectra for (a) $\left[\mathrm{C}_{n} \mathrm{C}_{1} \mathrm{Pip}\right]\left[\mathrm{Tf}_{2} \mathrm{~N}\right]$ and $(\mathrm{b})\left[\mathrm{C}_{n} \mathrm{C}_{1} \mathrm{Pip}\right] \mathrm{Br}$, where $n=2-12$.

\section{Electronic environment of the nitrogen regions: Impact of the anion}

Figure 3 illustrates the $\mathrm{N} 1 \mathrm{~s}$ spectra for $\left[\mathrm{C}_{8} \mathrm{C}_{1} \mathrm{Pip}\right]\left[\mathrm{Tf}_{2} \mathrm{~N}\right],\left[\mathrm{C}_{8} \mathrm{C}_{1} \mathrm{Pip}\right]\left[\mathrm{PF}_{6}\right]$ and $\left[\mathrm{C}_{8} \mathrm{C}_{1} \mathrm{Pip}\right] \mathrm{Br}$. The $\mathrm{N}_{\text {cation }} 1 \mathrm{~s}$ binding energy for $\left[\mathrm{C}_{8} \mathrm{C}_{1} \mathrm{Pip}\right]\left[\mathrm{Tf}_{2} \mathrm{~N}\right]$ is $402.5 \mathrm{eV}$. By contrast, one for $\left[\mathrm{C}_{8} \mathrm{C}_{1} \mathrm{Pip}\right] \mathrm{Br}$ is at $402.1 \mathrm{eV}$, which is $0.4 \mathrm{eV}$ lower than that of $\left[\mathrm{C}_{8} \mathrm{C}_{1} \operatorname{Pip}\right]\left[\mathrm{Tf}_{2} \mathrm{~N}\right]$. The $\mathrm{N}$ $1 \mathrm{~s}$ binding energy for $\left[\mathrm{C}_{8} \mathrm{C}_{1} \mathrm{Pip}\right]\left[\mathrm{PF}_{6}\right]$ is $402.4 \mathrm{eV}$, which is in between of $\left[\mathrm{C}_{8} \mathrm{C}_{1} \mathrm{Pip}\right]\left[\mathrm{Tf}_{2} \mathrm{~N}\right]$ and $\left[\mathrm{C}_{8} \mathrm{C}_{1} \mathrm{Pip}\right] \mathrm{Br}$. It indicates that the $\mathrm{N} 1 \mathrm{~s}$ binding energies for these three ILs follow the trend: $\left[\mathrm{Tf}_{2} \mathrm{~N}\right]^{-}>\left[\mathrm{PF}_{6}\right]^{-}>\mathrm{Br}$. This observation is in good agreement with previous XPS investigation for other families of ionic liquids.

This phenomenon can be interpreted as below. For the more basic anion, the charge-transfer effect from the anion to the cation is significant, which leads to the increase of the electron density on nitrogen centre. Consequently, the $\mathrm{N} 1 \mathrm{~s}$ binding energy is lower. The opposite is also true for the less basic anion. 
The same trend can also be found for $\mathrm{C}_{\text {hetero }} 1 \mathrm{~s}$ binding energy, which can be found in detail in Table 3.

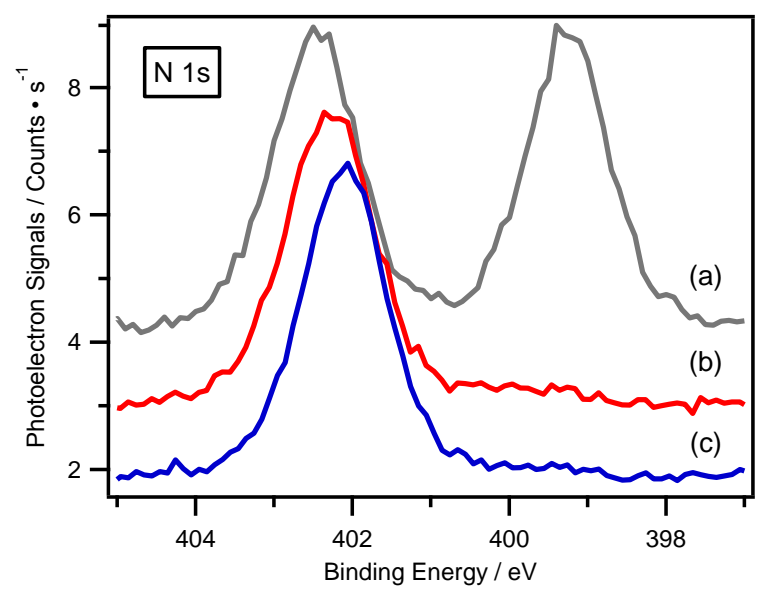

Figure $3 \mathrm{~N}$ 1s spectra for $(\mathrm{a})\left[\mathrm{C}_{8} \mathrm{C}_{1} \mathrm{Pip}\right]\left[\mathrm{Tf}_{2} \mathrm{~N}\right]$, (b) $\left[\mathrm{C}_{8} \mathrm{C}_{1} \mathrm{Pip}\right]\left[\mathrm{PF} \mathrm{F}_{6}\right]$ and $(\mathrm{c})\left[\mathrm{C}_{8} \mathrm{C}_{1} \mathrm{Pip}\right] \mathrm{Br}$.

\section{$\left[\mathrm{C}_{8} \mathrm{C}_{1} \mathrm{Pip}\right]^{+}$versus $\left[\mathrm{C}_{8} \mathrm{Py}\right]^{+}$: Impact of charge delocalisation on hetero carbons}

The positive charge delocalisation within the cation can have significant electronic influence upon the cation-based components, and subsequently the anion-based components. In the following two sections, $\left[\mathrm{C}_{8} \mathrm{C}_{1} \mathrm{Pip}\right]^{+}$cation is compared with a structurally similar charge delocalised cation, $\left[\mathrm{C}_{8} \mathrm{Py}\right]^{+}$.

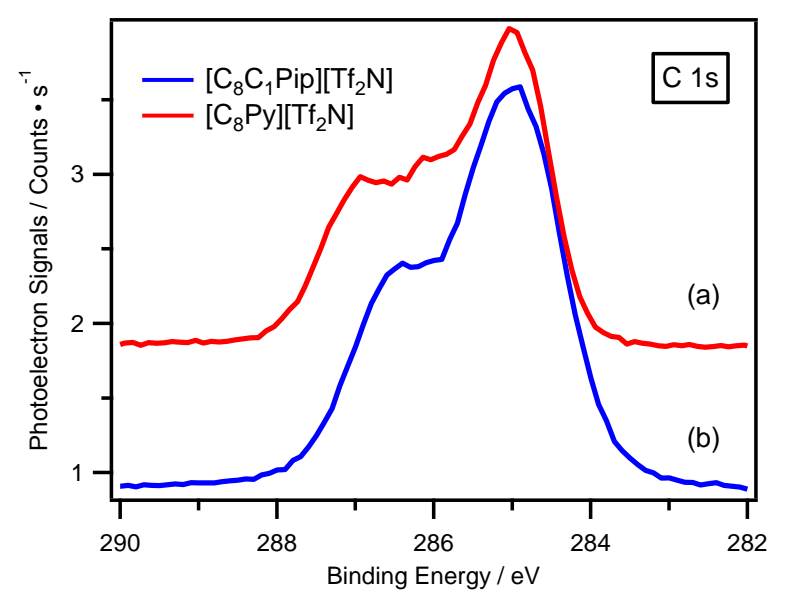

Figure 4 Cationic regions of $\mathrm{C} 1 \mathrm{~s}$ XP spectra for $(\mathrm{a})\left[\mathrm{C}_{8} \mathrm{Py}\right]\left[\mathrm{Tf}_{2} \mathrm{~N}\right]$ and $(\mathrm{b})\left[\mathrm{C}_{8} \mathrm{C}_{1} \mathrm{Pip}\right]\left[\mathrm{Tf}_{2} \mathrm{~N}\right]$.

Figure 4 compares the cationic region of $\mathrm{C} 1 \mathrm{~s} \mathrm{XP}$ spectra, especially the hetero carbon region, between $\left[\mathrm{C}_{8} \mathrm{C}_{1} \mathrm{Pip}\right]\left[\mathrm{Tf}_{2} \mathrm{~N}\right]$ and $\left[\mathrm{C}_{8} \mathrm{Py}\right]\left[\mathrm{Tf}_{2} \mathrm{~N}\right]$. It is clear that the $\mathrm{C}_{\text {hetero }}$ 1s binding energy of $\left[\mathrm{C}_{8} \mathrm{Py}\right]\left[\mathrm{Tf}_{2} \mathrm{~N}\right]$ is much higher than that of $\left[\mathrm{C}_{8} \mathrm{C}_{1} \mathrm{Pip}\right]\left[\mathrm{Tf} \mathrm{f}_{2} \mathrm{~N}\right]$. Due to the positive charge delocalisation, the hetero carbon component present in $\left[\mathrm{C}_{8} \mathrm{Py}\right]^{+}$is much more positively charged. However, there is no delocalisation system within the structure of $\left[\mathrm{C}_{8} \mathrm{C}_{1} \mathrm{Pip}\right]^{+}$, leading to the reality that the positive charge is solely located on the nitrogen centre. As a result, the $\mathrm{C}_{\text {hetero }} 1 \mathrm{~s}$ binding energy for $\left[\mathrm{C}_{8} \mathrm{C}_{1} \mathrm{Pip}\right]\left[\mathrm{Tf}_{2} \mathrm{~N}\right]$ is found $\sim 0.5 \mathrm{eV}(0.463 \mathrm{eV}$ in three decimal places) lower than that 
of $\left[\mathrm{C}_{8} \mathrm{Py}\right]\left[\mathrm{Tf}_{2} \mathrm{~N}\right]$.

A same binding energy shift can also be observed for Br- ILs (see Table 3 for details). It suggests that by switching the cation from $\left[\mathrm{C}_{8} \mathrm{C}_{1} \mathrm{Pip}\right]^{+}$to $\left[\mathrm{C}_{8} \mathrm{Py}\right]^{+}$, it is feasible to tune the electronic environment of the cationic hetero carbons, with only subtle impact from the anion basicity.

However, such a shift is not measurable for $\mathrm{N}_{\text {cation }}$ component. As shown in Table 3, $\mathrm{N}_{\text {cation }} 1 \mathrm{~s}$ binding energies are identical for $\left[\mathrm{C}_{8} \mathrm{C}_{1} \mathrm{Pip}\right]^{+}$and $\left[\mathrm{C}_{8} \mathrm{Py}\right]^{+}$ILs, with a definite anion. Although the positive charge is delocalised over $\left[\mathrm{C}_{8} \mathrm{Py}\right]^{+}$cation, the nitrogen is in $\mathrm{sp}^{2}$ hybridisation; whilst it is in $\mathrm{sp}^{3}$ hybridisation for $\left[\mathrm{C}_{8} \mathrm{C}_{1} \mathrm{Pip}\right]^{+}$, meaning that an additional methyl group is bonded to the nitrogen centre which gives rise to the increase of electron density of the nitrogen centre. The two sets of effect, i.e. charge delocalisation in the case of $\left[\mathrm{C}_{8} \mathrm{Py}\right]^{+}$and the inductive electron donation from the additional methyl group in the case of $\left[\mathrm{C}_{8} \mathrm{C}_{1} \mathrm{Pip}\right]^{+}$seems to have impact in similar magnitude upon the electronic environment of the nitrogen centre. Consequently, the same (within the error) $\mathrm{N}_{\text {cation }} 1 \mathrm{~s}$ binding energy is measured for $\left[\mathrm{C}_{8} \mathrm{C}_{1} \mathrm{Pip}\right]^{+}$and $\left[\mathrm{C}_{8} \mathrm{Py}\right]^{+}$ILs.

By carefully considering the $\mathrm{N}_{\text {cation }} 1 \mathrm{~s}$ binding energy shift, it concludes that although within the XPS experimental error, the shift is more pronounced in the case of $\left[\mathrm{Tf}_{2} \mathrm{~N}\right]^{-}$(more than $0.1 \mathrm{eV}$; whereas $\sim 0.0 \mathrm{eV}$ for $\mathrm{Br}$ ). It has been widely accepted that the charge-transfer in ILs is dependent upon the basicity of the anion. In the case of [Tf $\left.f_{2} \mathrm{~N}\right]$; the weak charge-transfer causes the stronger electron donation effect from the methyl group within $\left[\mathrm{C}_{8} \mathrm{C}_{1} \mathrm{Pip}\right]^{+}$towards the cationic nitrogen centre, resulting in a more noticeable change in electronic environment, which explains the slightly large $N_{\text {cation }} 1 \mathrm{~s}$ binding energy shift between $\left[\mathrm{C}_{8} \mathrm{Py}\right]\left[\mathrm{Tf}_{2} \mathrm{~N}\right]$ and $\left[\mathrm{C}_{8} \mathrm{C}_{1} \mathrm{Pip}\right]\left[\mathrm{Tf}_{2} \mathrm{~N}\right]$.

\section{$\left[\mathrm{C}_{8} \mathrm{C}_{1} \mathrm{Pip}\right]^{+}$versus $\left[\mathrm{C}_{8} \mathrm{Py}\right]^{+}$: Impact of charge delocalisation on the anion-based components}

The positive charge delocalisation makes the protons ( $\alpha$ to the positively charged nitrogen centre) within pyridinium significantly more acidic than that present in piperdinium. As reported in the literature, when associated with the same anion, i.e. $\left[\mathrm{Tf}_{2} \mathrm{~N}\right]^{-}$, the Kamlet-Taft hydrogen donating ability $(\alpha)$ for $\left[\mathrm{C}_{4} \mathrm{Py}\right]^{+}$is 0.51 , which is much higher than that for $\left[\mathrm{C}_{4} \mathrm{C}_{1} \mathrm{Pip}\right]^{+}(0.43) .{ }^{27}$ The less acidic cation can have more intense shielding on the point charge transferred from the anion to the cation. The electronic environment of the anion can be subsequently tuned by varying the cation.

Figure 5 shows a comparison of XP spectra for all anion-based components between $\left[\mathrm{C}_{8} \mathrm{C}_{1} \mathrm{Pip}\right]\left[\mathrm{Tf}_{2} \mathrm{~N}\right]$ and $\left[\mathrm{C}_{8} \mathrm{Py}\right]\left[\mathrm{Tf}_{2} \mathrm{~N}\right]$. At first glance, it is observed that binding energies for all anion-based components of $\left[\mathrm{C}_{8} \mathrm{C}_{1} \mathrm{Pip}\right]\left[\mathrm{Tf}_{2} \mathrm{~N}\right]$ shift towards lower values, compared to those of $\left[\mathrm{C}_{8} \mathrm{Py}\right]\left[\mathrm{Tf}_{2} \mathrm{~N}\right]$. This is because $\left[\mathrm{C}_{8} \mathrm{C}_{1} \mathrm{Pip}\right]^{+}$can shield more partial charges transferred from $\left[\mathrm{Tf}_{2} \mathrm{~N}\right]$; , leaving the anion bearing more point negative charges. However, as the charge-transfer effect in the case of $\left[\mathrm{Tf}_{2} \mathrm{~N}\right]$ - is weak, the difference in 
charge shielding between $\left[\mathrm{C}_{8} \mathrm{C}_{1} \mathrm{Pip}\right]^{+}$and $\left[\mathrm{C}_{8} \mathrm{Py}\right]^{+}$is not perfectly noticeable. After carefully considering the magnitude of the binding energy shift, it suggests that the binding energy shift for $F 1 s, N_{\text {anion }} 1 \mathrm{~s}, \mathrm{C}_{\text {anion }} 1 \mathrm{~s}$ and $\mathrm{S} 2 \mathrm{p}_{3 / 2}$ is within the experimental error (as shown in Figures 4a, 4c-4e). On the other hand, a noticeable change in binding energy is found for $0 \mathrm{1s}$, which is more than $0.2 \mathrm{eV}$ (see Figure $4 \mathrm{~b}$ ). This observation further confirms that for the less basic anion, the charge shielding effect is more concentrated on the component bearing more point charges, i.e. oxygen within $\left[\mathrm{Tf}_{2} \mathrm{~N}\right]^{-33-35}$ Binding energies for all elements can be found in Table 3 in detail.
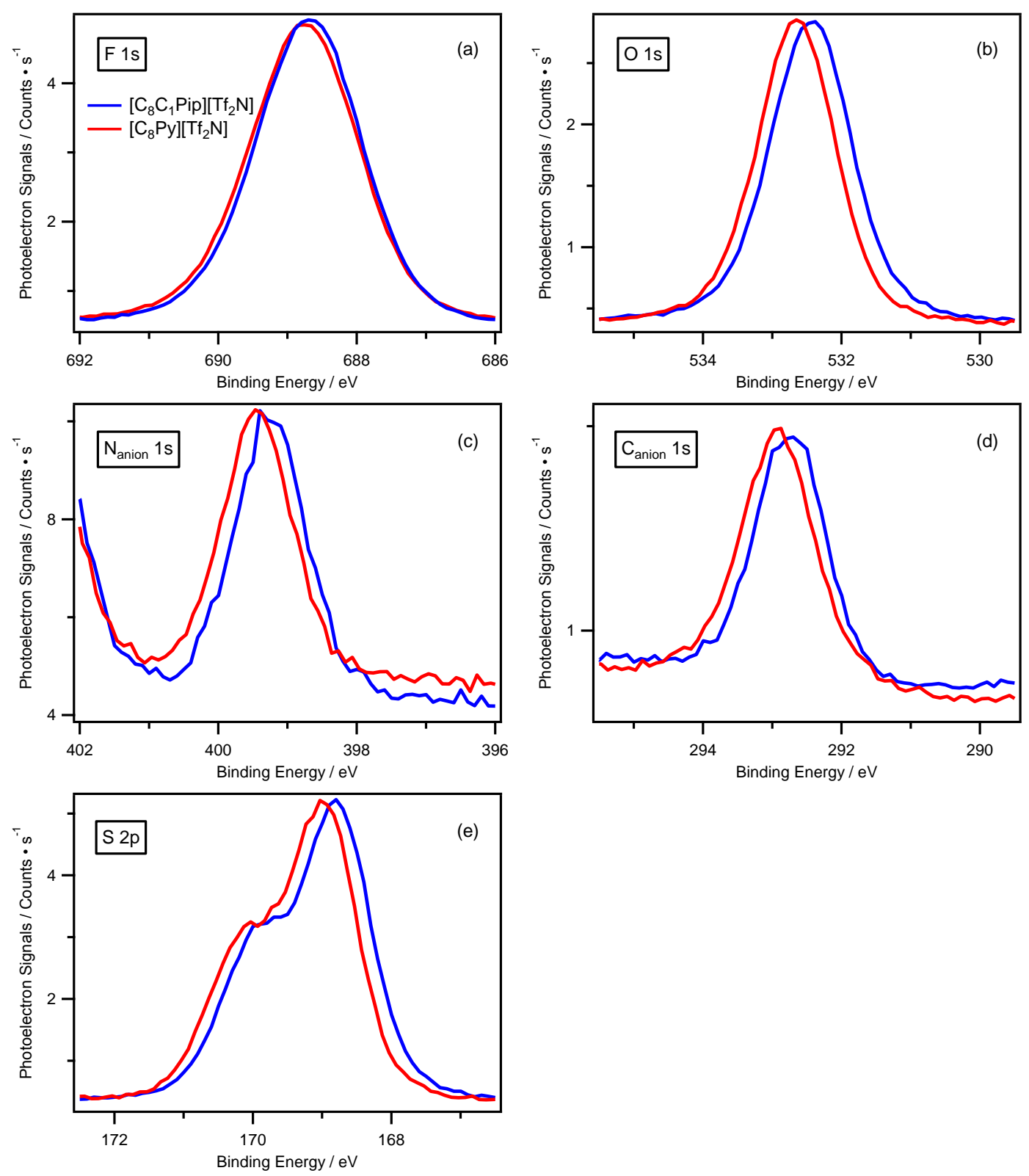

Figure 5 XP spectra of $\left[\mathrm{C}_{8} \mathrm{C}_{1} \mathrm{Pip}\right]\left[\mathrm{Tf}_{2} \mathrm{~N}\right]$ and $\left[\mathrm{C}_{8} \mathrm{Py}\right]\left[\mathrm{Tf} \mathrm{f}_{2} \mathrm{~N}\right]$ : (a) F 1s, (b) $\mathrm{O} 1 \mathrm{~s},(\mathrm{c}) \mathrm{N}_{\text {anion }} 1 \mathrm{~s}$, (d) $\mathrm{C}_{\text {anion }} 1 \mathrm{~s}$ and (e) S $2 \mathrm{p}$.

For the more basic anion, i.e. Br-, the measured binding energy shift of $\mathrm{Br} 3 \mathrm{~d}_{5 / 2}$ is more than $0.2 \mathrm{eV}$, which can reflect the change in electronic environment of the anion. 
$\mathrm{Br}^{-}$as one of the most basic anions can transfer much more point charges to the caiton. Consequently, when switching the cation from $\left[\mathrm{C}_{8} \mathrm{Py}\right]^{+}$to $\left[\mathrm{C}_{8} \mathrm{C}_{1} \mathrm{Pip}\right]^{+}$, the charge shielding effect is much stronger, enabling a measurable $\mathrm{Br} 3 \mathrm{~d}_{5 / 2}$ binding energy shift. Figure 6 summaries in detail the shift in binding energy for each anion-based component for the two anions.

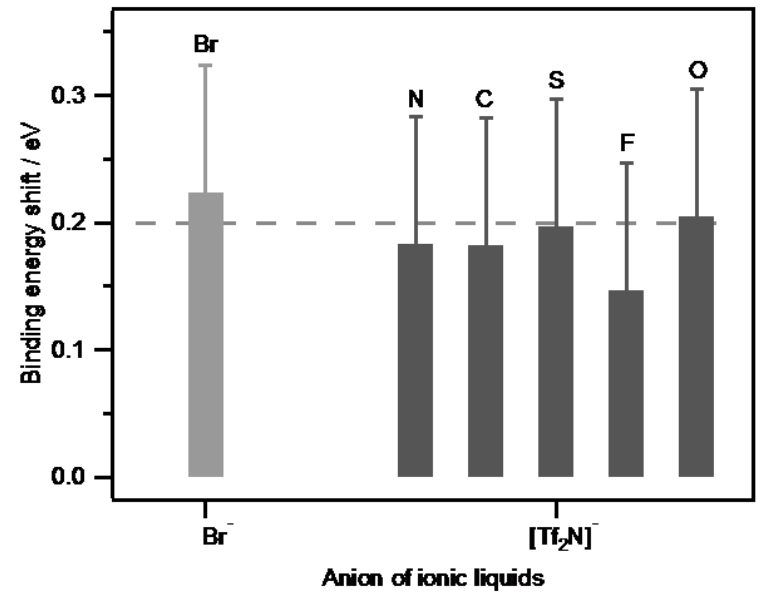

Figure 6 Binding energy shift for each anion-based component between $\left[\mathrm{C}_{8} \mathrm{Py}\right]^{+}$and $\left[\mathrm{C}_{8} \mathrm{C}_{1} \mathrm{Pip}\right]^{+}$ionic liquids for the two anions. 
Table 3 Binding energies in eV of all elements for all ionic liquids studied in this paper.

\begin{tabular}{|c|c|c|c|c|c|c|c|c|c|c|c|}
\hline \multirow{2}{*}{ Ionic liquids } & \multicolumn{11}{|c|}{ Binding energy / eV } \\
\hline & $\mathrm{N}_{\text {cation }} 1 \mathrm{~s}$ & Chetero 1s & $\mathrm{C}_{\text {inter }} 1 \mathrm{~s}$ & $\mathrm{C}_{\text {aliphatic }} 1 \mathrm{~s}$ & $\mathrm{C}_{\text {anion }} 1 \mathrm{~s}$ & $\mathrm{~N}_{\text {anion }} 1 \mathrm{~s}$ & F 1s & $01 \mathrm{~s}$ & $\mathrm{~S} 2 \mathrm{p}_{3 / 2}$ & $\mathrm{P} 2 \mathrm{p}_{3 / 2}$ & $\operatorname{Br} 3 d_{5 / 2}$ \\
\hline$\left[\mathrm{C}_{8} \mathrm{C}_{1} \mathrm{Pip}\right]\left[\mathrm{Tf}_{2} \mathrm{~N}\right]$ & 402.5 & 286.6 & & 285.0 & 292.7 & 399.3 & 688.7 & 532.4 & 168.8 & & \\
\hline$\left[\mathrm{C}_{8} \mathrm{C}_{1} \mathrm{Pip}\right]\left[\mathrm{PF}_{6}\right]$ & 402.4 & 286.5 & & 285.0 & & & 686.5 & & & 136.4 & \\
\hline$\left[\mathrm{C}_{8} \mathrm{C}_{1} \mathrm{Pip}\right] \mathrm{Br}$ & 402.1 & 286.1 & & 285.0 & & & & & & & 67.3 \\
\hline$\left[\mathrm{C}_{2} \mathrm{C}_{1} \mathrm{Pip}\right]\left[\mathrm{Tf}_{2} \mathrm{~N}\right]$ & 402.5 & 286.6 & & 285.3 & 292.8 & 399.2 & 688.7 & 532.4 & 168.8 & & \\
\hline$\left[\mathrm{C}_{4} \mathrm{C}_{1} \mathrm{Pip}\right]\left[\mathrm{Tf}_{2} \mathrm{~N}\right]$ & 402.5 & 286.6 & & 285.2 & 292.7 & 399.3 & 688.7 & 532.5 & 168.8 & & \\
\hline$\left[\mathrm{C}_{12} \mathrm{C}_{1} \mathrm{Pip}\right]\left[\mathrm{Tf}_{2} \mathrm{~N}\right]$ & 402.5 & 286.6 & & 284.9 & 292.7 & 399.3 & 688.7 & 532.4 & 168.8 & & \\
\hline$\left[\mathrm{C}_{2} \mathrm{C}_{1} \mathrm{Pip}\right] \mathrm{Br}$ & 402.1 & 286.1 & & 285.0 & & & & & & & 67.3 \\
\hline$\left[\mathrm{C}_{4} \mathrm{C}_{1} \mathrm{Pip}\right] \mathrm{Br}$ & 402.1 & 286.1 & & 285.0 & & & & & & & 67.3 \\
\hline$\left[\mathrm{C}_{12} \mathrm{C}_{1} \mathrm{Pip}\right] \mathrm{Br}$ & 402.1 & 286.2 & & 285.0 & & & & & & & 67.3 \\
\hline$\left[\mathrm{C}_{8} \mathrm{Py}\right]\left[\mathrm{Tf}_{2} \mathrm{~N}\right]^{20}$ & 402.6 & 287.0 & 286.1 & 285.0 & 292.9 & 399.4 & 688.8 & 532.6 & 169.0 & & \\
\hline$\left[\mathrm{C}_{8} \mathrm{Py}\right] \mathrm{Br}^{20}$ & 402.1 & 286.6 & 285.7 & 285.0 & & & & & & & 67.5 \\
\hline
\end{tabular}




\section{Conclusions}

A systematic XPS study of piperidinium ionic liquids is conducted. A fitting model for the carbon region is developed. The effect of the alkyl substituent length on the $\mathrm{C}_{\text {aliphatic }} 1 \mathrm{~s}$ binding energies is demonstrated in detail by varying the alkyl chain length from ethyl to dodecyl. The impact of the anion basicity on the electronic environment of the cation-based component is investigated by employing three common anions including $\left[\mathrm{Tf}_{2} \mathrm{~N}\right]-,\left[\mathrm{PF}_{6}\right]^{-}$and $\mathrm{Br}$. Our results show that the $\mathrm{N}$ 1s binding energies for these ILs follow the trend: $\left[\mathrm{Tf}_{2} \mathrm{~N}\right]^{-}>\left[\mathrm{PF}_{6}\right]^{-}>\mathrm{Br}$. It offers a strategy for the design of ILs with desired physicochemical properties, by changing the basicity of the anion.

The impact of the charge delocalisation upon the electronic environment of the hetero carbon component is compared between $\left[\mathrm{C}_{8} \mathrm{C}_{1} \mathrm{Pip}\right]^{+}$and $\left[\mathrm{C}_{8} \mathrm{Py}\right]^{+}$. Due to the positive charge delocalisation, the $\mathrm{C}_{\text {hetero }}$ component present in $\left[\mathrm{C}_{8} \mathrm{Py}\right]^{+}$is much more positively charged, and thus shows higher binding energy. The binding energy shift is $\sim 0.5 \mathrm{eV}$. Such an effect is found with negligible impact from the anion. This observation shows good agreement with the relative stability of the two cations; piperidinium ILs are usually more stable than their structurally similar pyridinium analogues. However, for the cationic nitrogen, the binding energy is identical between $\left[\mathrm{C}_{8} \mathrm{C}_{1} \mathrm{Pip}\right]^{+}$and $\left[\mathrm{C}_{8} \mathrm{Py}\right]^{+}$. This is because within $\left[\mathrm{C}_{8} \mathrm{C}_{1} \mathrm{Pip}\right]^{+}$, there is an inductive electron donation from the additional methyl group towards the cationic nitrogen, impacting the electron density in a similar magnitude.

The effect of the charge delocalisation on the electronic environment of the anion is also investigated by comparing $\left[\mathrm{C}_{8} \mathrm{C}_{1} \mathrm{Pip}\right]^{+}$versus $\left[\mathrm{C}_{8} \mathrm{Py}\right]^{+}$. Due to the positive charge delocalisation, $\left[\mathrm{C}_{8} \mathrm{Py}\right]^{+}$is more acidic than $\left[\mathrm{C}_{8} \mathrm{C}_{1} \mathrm{Pip}\right]^{+}$. As a result, the charge shielding effect of $\left[\mathrm{C}_{8} \mathrm{C}_{1} \mathrm{Pip}\right]^{+}$is stronger than that of $\left[\mathrm{C}_{8} \mathrm{Py}\right]^{+}$. The anion should be subsequently left bearing more negative charge. For the more basic anion, this shielding effect is reflected on the lowering of the binding energy, i.e. $\mathrm{Br} 3 \mathrm{~d}_{5 / 2}$ binding energy for $\left[\mathrm{C}_{8} \mathrm{C}_{1} \mathrm{Pip}\right] \mathrm{Br}$ is found more than $0.2 \mathrm{eV}$ lower than that of $\left[\mathrm{C}_{8} \mathrm{Py}\right] \mathrm{Br}$. For the less basic anion, i.e. $\left[\mathrm{Tf}_{2} \mathrm{~N}\right]$;, the charge shielding effect can only affect of the electronic environment of the component bearing the most amount of point charges, i.e. oxygen. These findings provide insights for the tuning of ILs properties by simply modifying the cation, in particularly to the structurally similar analogue.

\section{Acknowledgements}

SM thanks Liaoning Provincial Foundation of Science and Technology (20180550482) for financial support. SM is also grateful to China Scholarship Council for the grant of a scholarship under State Scholarship Fund (201808210439) as a Visiting Scholar in Oak Ridge National Laboratory (ORNL). HML and SD are partly supported by U.S. Department of Energy, Office of Science, Basic Energy Sciences, Chemical Sciences, Geosciences, and Biosciences Division. Drs. Jun Qu and Harry Meyer 
III from ORNL are acknowledged for XPS training and helpful discussions.

\section{Reference}

1. T. Welton, Coord. Chem. Rev., 2004, 248, 2459-2477.

2. V. I. Pârvulescu and C. Hardacre, Chem. Rev., 2007, 107, 2615-2665.

3. F. van Rantwijk and R. A. Sheldon, Chem. Rev., 2007, 107, 2757-2785.

4. R. A. Sheldon, R. M. Lau, M. J. Sorgedrager, F. van Rantwijk and K. R. Seddon, Green Chem., 2002, 4, 147-151.

5. J. P. Mikkola, P. Virtanen, K. Kordas, H. Karhu and T. O. Salmi, Appl. Catal. A-Gen., 2007, 328, 68-76.

6. C. P. Mehnert, Chem.-Eur. J., 2004, 11, 50-56.

7. D. R. Macfarlane, M. Forsyth, P. C. Howlett, J. M. Pringle, J. Sun, G. Annat, W. Neil and E. I. Izgorodina, Acc. Chem. Res., 2007, 40, 1165-1173.

8. Z. Zhou, H. Matsumoto and K. Tatsumi, Chem.-Eur. J., 2006, 12, 2196-2212.

9. Y. Cao and T. Mu, Ind. Eng. Chem. Res., 2014, 53, 8651-8664.

10. J. M. Crosthwaite, M. J. Muldoon, J. K. Dixon, J. L. Anderson and J. F. Brennecke, J. Chem. Thermodyn., 2005, 37, 559-568.

11. M. Shukla, H. Noothalapati, S. Shigeto and S. Saha, Vib. Spectrosc., 2014, 75, 107-117.

12. H. Tokuda, S. Tsuzuki, M. A. B. H. Susan, K. Hayamizu and M. Watanabe, Journal of Physical Chemistry B, 2006, 110, 19593-19600.

13. A. Bhattacharjee, P. J. Carvalho and J. A. P. Coutinho, Fluid Phase Equilib., 2014, 375, 80-88.

14. K. Matsumoto, R. Hagiwara and Y. Ito, Electrochem. Solid State Lett., 2004, 7, E41-E44.

15. Y. Traore, S. Legeai, S. Diliberto, G. Arrachart, S. Pellet-Rostaing and M. Draye, Electrochim. Acta, 2011, 58, 532-540.

16. E. F. Smith, I. J. Villar-Garcia, D. Briggs and P. Licence, Chem. Commun., 2005, 5633-5635.

17. F. Maier, J. M. Gottfried, J. Rossa, D. Gerhard, P. S. Schulz, W. Schwieger, P. Wasserscheid and H.-P. Steinrück, Angew. Chem.-Int. Edit., 2006, 45, 7778-7780.

18. I. J. Villar-Garcia, E. F. Smith, A. W. Taylor, F. Qiu, K. R. J. Lovelock, R. G. Jones and P. Licence, Phys. Chem. Chem. Phys., 2011, 13, 2797-2808.

19. Y. Liu, X. Chen, S. Men, P. Licence, F. Xi, Z. Ren and W. Zhu, Phys. Chem. Chem. Phys., 2019, 21, 11058-11065.

20. S. Men, D. S. Mitchell, K. R. J. Lovelock and P. Licence, ChemPhysChem, 2015, 16, 2211-2218.

21. S. Men, K. R. J. Lovelock and P. Licence, Phys. Chem. Chem. Phys., 2011, 13, 15244-15255. 
22. S. Men, B. B. Hurisso, K. R. J. Lovelock and P. Licence, Phys. Chem. Chem. Phys., 2012, 14, 5229-5238.

23. R. K. Blundell and P. Licence, Phys. Chem. Chem. Phys., 2014, 16, 15278-15288.

24. A. R. Santos, R. K. Blundell and P. Licence, Phys. Chem. Chem. Phys., 2015, 17, 11839-11847.

25. S. Men and P. Licence, Chem. Phys. Lett., 2017, 681, 40-43.

26. T. Cremer, C. Kolbeck, K. R. J. Lovelock, N. Paape, R. Wölfel, P. S. Schulz, P. Wasserscheid, H. Weber, J. Thar, B. Kirchner, F. Maier and H.-P. Steinrück, Chem.-Eur. J., 2010, 16, 9018-9033.

27. S. Spange, R. Lungwitz and A. Schade, J. Mol. Liq., 2014, 192, 137-143.

28. A. W. Taylor, K. R. J. Lovelock, A. Deyko, P. Licence and R. G. Jones, Phys. Chem. Chem. Phys., 2010, 12, 1772-1783.

29. C. D. Wagner, L. E. Davis, M. V. Zeller, J. A. Taylor, R. H. Raymond and L. H. Gale, Surf. Interface Anal., 1981, 3, 211-225.

30. D. Briggs and J. T. Grant, eds., Surface Analysis by Auger and X-ray Photoelectron Spectroscopy, IMPublications, Manchester, 2003.

31. G. Beamson, D. T. Clark, J. Kendrick and D. Briggs, Journal of Electron Spectroscopy and Related Phenomena, 1991, 57, 79-90.

32. D. Briggs and G. Beamson, Anal. Chem., 1992, 64, 1729-1736.

33. P. A. Hunt, I. R. Gould and B. Kirchner, Aust. J. Chem., 2007, 60, 9-14.

34. S. Tsuzuki, H. Tokuda, K. Hayamizu and M. Watanabe, J. Phys. Chem. B, 2005, 109, 16474-16481.

35. J. N. C. Lopes and A. A. H. Padua, J. Phys. Chem. B, 2004, 108, 16893-16898. 